Iranian Journal of Breast Diseases. 2020;13(1):8-16.

\section{Original Article \\ Effect of Foot Reflexology Massage on Pain and Need for Opioid in Breast Cancer Patients Undergoing Mastectomy after Radiotherapy: A Randomized Clinical Trial}

\author{
Eghdam-Zamiri $\mathbf{R}^{1}$, Dorosti $\mathbf{A}^{2^{*}}$ \\ ${ }^{1}$ Department of Radiology, Faculty of Medicine, Tabriz University of Medical \\ Sciences, Tabriz, Iran \\ 2 Department of Anesthesiology, Faculty of Medicine, Tabriz University of \\ Medical Sciences, Tabriz, Iran
}

Receive: 7/10/2019 Accepted: 30/12/2019

${ }^{*}$ Corresponding Author: Dorostia44@yshoo.com

Ethics Approval: IR.TBZMED.REC.1397.1059

\begin{abstract}
Introduction: Because of not applying analgesics in mastectomy candidates and the complications of analgesic therapy in these patients on the one hand and increased pain intensity in patients who undergo mastectomy following radiotherapy on the other hand, the present study aimed to evaluate foot reflexology massage on pain and the need for opioids in breast cancer patients undergoing mastectomy after radiotherapy.

Methods: This randomized clinical trial was performed at Imam Reza Hospital, Tabriz, over the 10 months leading up to September 2019. Fifty-four patients (pilot-based estimation) were divided into two groups using a random-numbers table. The intervention group received foot massage every 6 hours (10 minutes per foot) for two days starting 4 hours after discharge. Patients' demographic information was recorded and pain intensity was measured with a visual analog scale. Chi-square tests, Fisher's exact test, and an independent $t$ test were used for data analysis on SPSS 21. $\mathrm{P}<0.05$ was considered significant.
\end{abstract}

Results: The control $(51.29 \pm 9.45)$ and the intervention $(52.03 \pm 8.96)$ groups were not different in pain intensity at baseline. However, after the intervention, a statistically significant difference was observed in pain intensity between the intervention and control groups $(20.12 \pm 6.75$ vs $49.88 \pm 8.95$, respectively, $\mathrm{P}=0.003$ ). Also, while there was no difference in pethidine consumption between the intervention $(29.99 \pm 4.49)$ and control $(29.18 \pm 4.50)$ groups before the intervention, the intervention group experienced a significant reduction in the medicine usage compared with the controls $(10.41 \pm 4.56$ vs $32.12 \pm 5.01, \mathrm{P}=0.001)$.

Conclusion: Foot reflexology massage reduced the severity of pain and the need for opioids in women who are candidates for mastectomy following radiation therapy.

Keywords: Reflexology Massage, Pain, Mastectomy, Radiotherapy 
مقاله برؤهشى

تاثير ماساز بازتابى كف با بر نياز به اوييوئيد و درد ناشى از جراحى

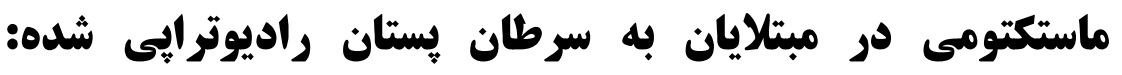
كار آزمايى بالينى تصادفى شده

$$
\text { رضا اقدام ضميرى'، عباسعلى درستى " }
$$

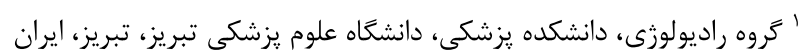

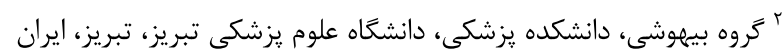

فصلنامه بيمارى هاى بستان ايران

1ra9: $17(1): 9-17$
جكيده

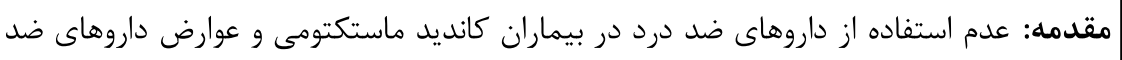

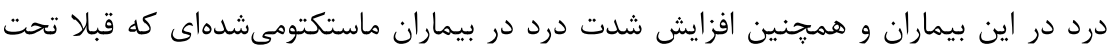

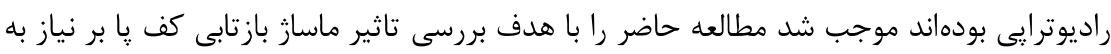

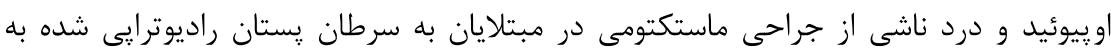

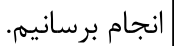

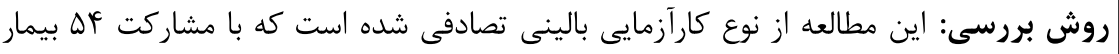

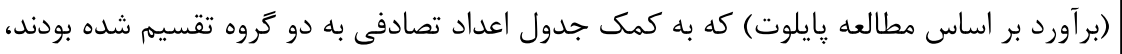

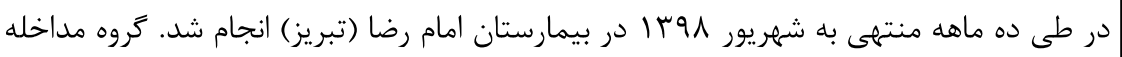

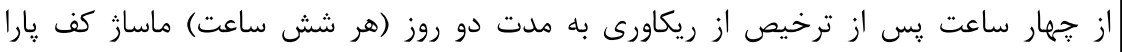

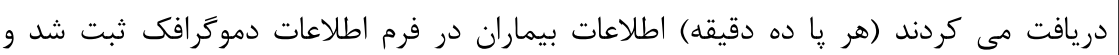

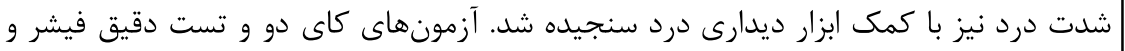

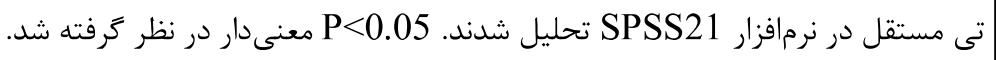

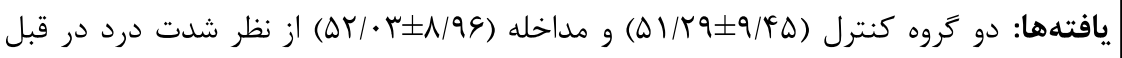

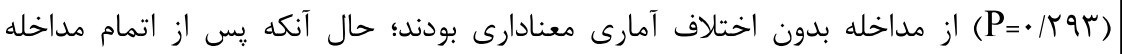

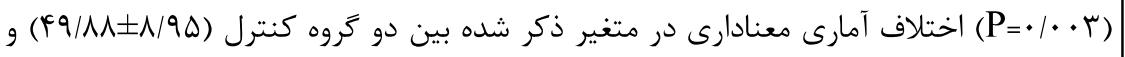

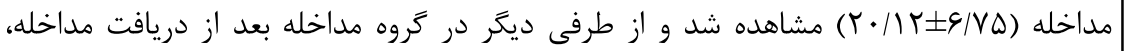

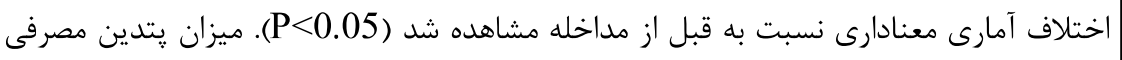

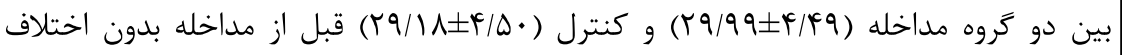

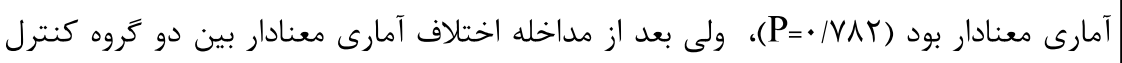

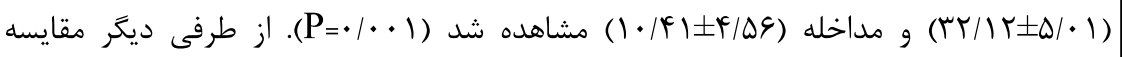

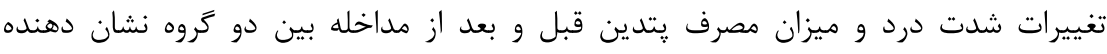

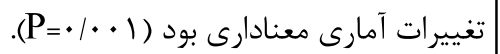

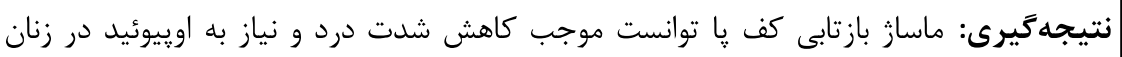

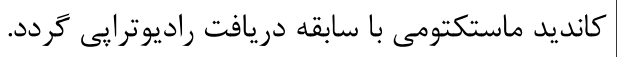
|وازههاى كليدى: ماساز باز تابى، كف ها، درد، ماستكتومى، راديوترايى، اوييوئيد

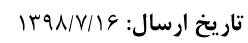

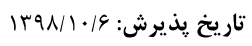

نشانى نويسنده مسئول: Dorostia44@yshoo.com 
مىشود. استفاده از اين روشها در اكثر بيماران توانسته است تا حد زيادى از نياز به داروى ضد درد بكاهد؛ با اين آنادئ

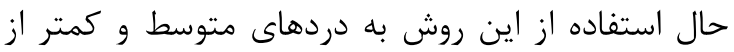

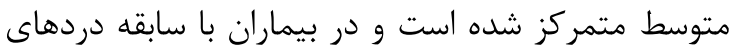
قبلى يا بيماران مستعد دردهاى بالاتر از متوسط كمتر بان بان

اين روش مورد بررسى و توجه قرار كرفتهاند (19). در طى خُندين مطالعه انجام شده در زمينه اثرات كاهنده

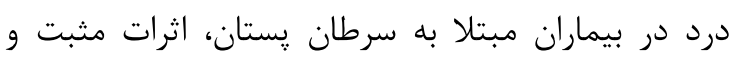

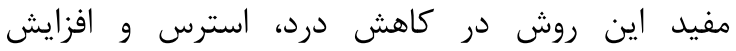

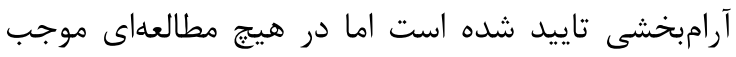

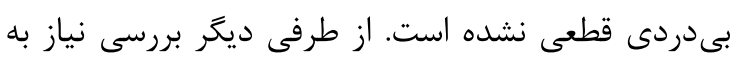

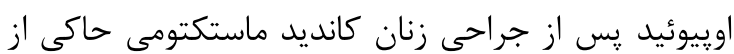

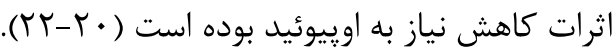

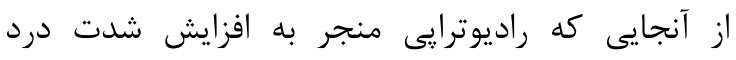

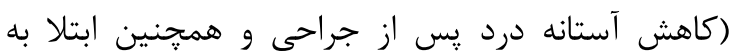

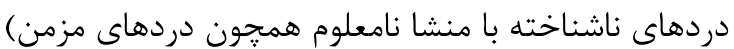

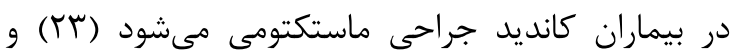

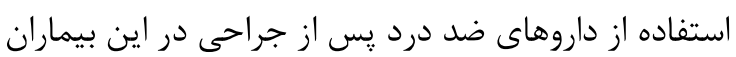

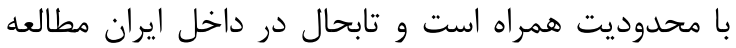

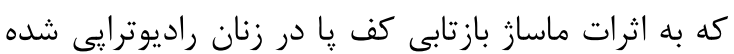

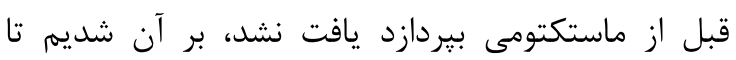

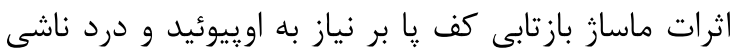
از جراحى ماستكتومى در مبتلايان به سرطان يستان

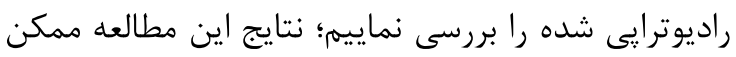

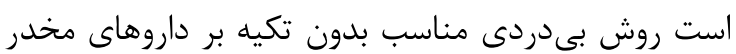

را إيشنهاد نمايد.

\section{مواد و روشها}

اين مطالعه از نوع كارآزمايى بالينى تصادفى شده بود كه

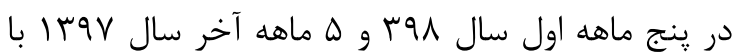
مشاركت هوه بيمار با رعايت معيارهاى ورود (حداقل سن سن مال

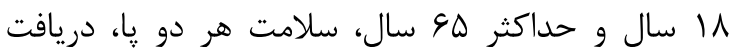

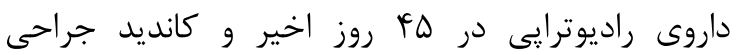

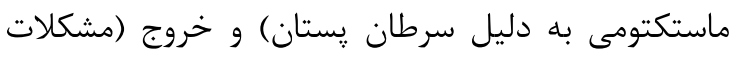

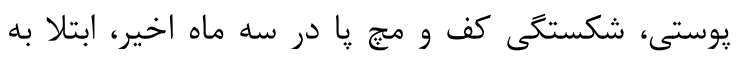

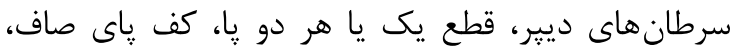

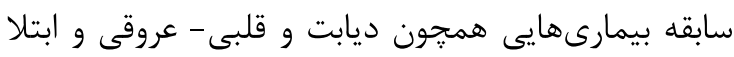

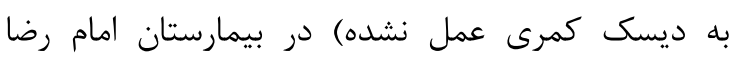
وابسته به دانشكاه علوم يزشكى تبريز انجام شد. انجام

\section{مقدمه}

درد يس از جراحى به عنوان يكى از عوارض شايع بوده كه

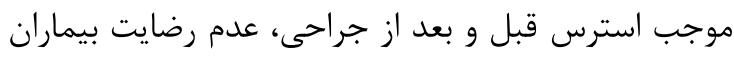

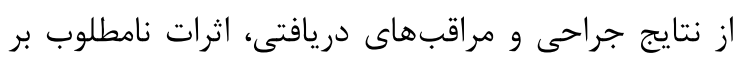

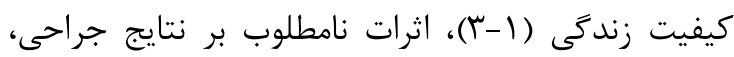
افزايش طول مدت بسترى در بيمارستان، افزايش نياز به

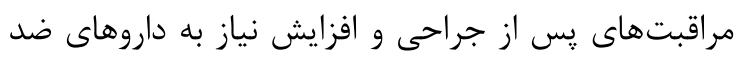

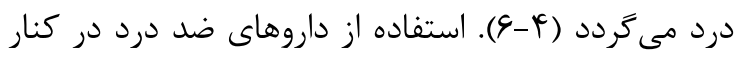

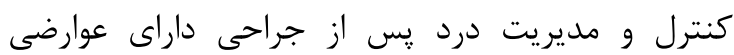

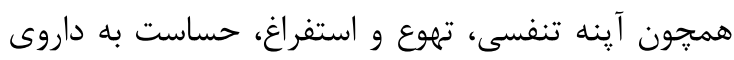

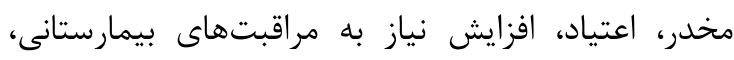
افزايش هزينههاى بيمارستانى و تاثيرات نامطلوب بر نتايج

اصلى جراحى مى كردد (V-9 (9).

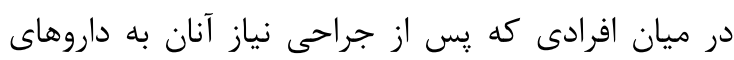
ضد درد بيشتر از سايرين مشاهده مىشود، بيمارن كانديد إن إنان

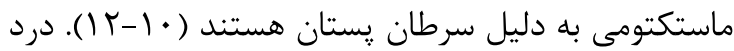

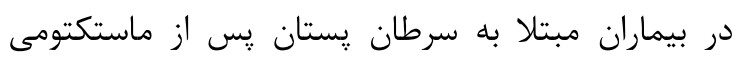

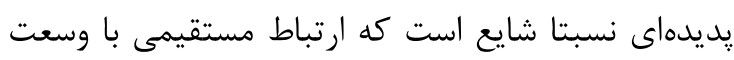
جراحى، دريافت داروهاى شيمى درمانى، دريافت داروهاى نائي

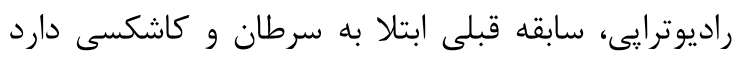

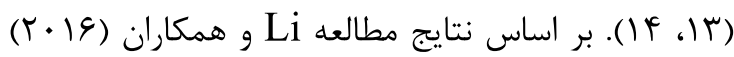
بيمارانى كه شيمىدرمانى و راديوترايى شدهاند، در صورتى

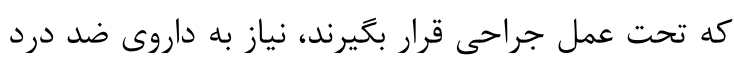

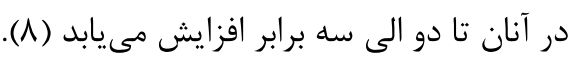

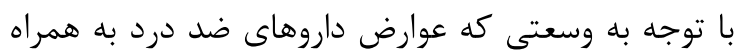
دارند، استفاده از روشهاى غير دارويى توسط يزشكان،

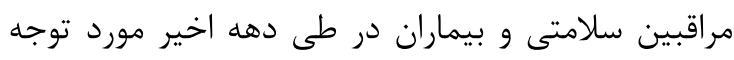

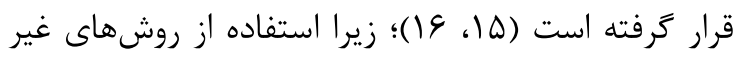

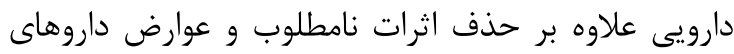

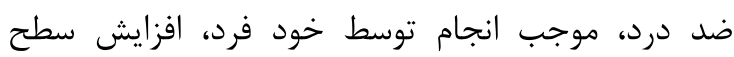

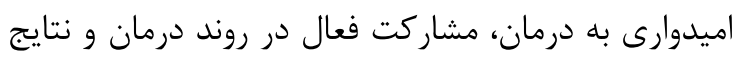

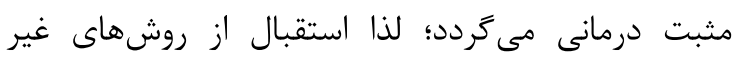

$$
\text { دارويى بيشتر از دهه اخير شده است (IV) }
$$

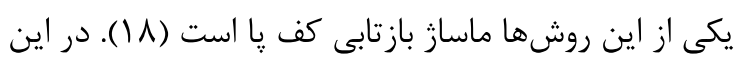

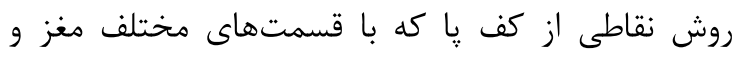

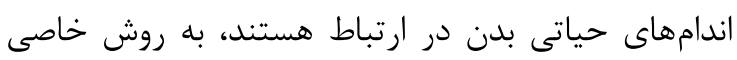
ماساز داده مىشوند و متعاقب آن مكانيسهمهايى در در مغز

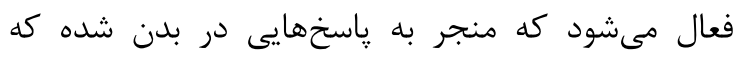

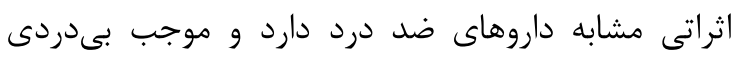




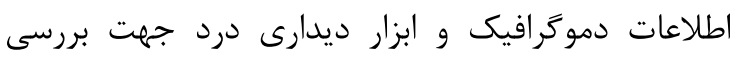

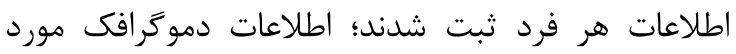
بررسى شامل سن، شغل، سطح تحصيلات، وضعيت تاهل،

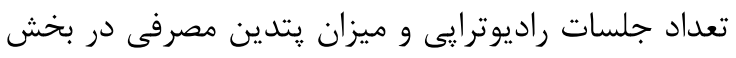
بود. جك ليست VAS شدت درد را در نمودارى كه شبيه خطكش است اندازميرى مىنمايد و از يك تا ... درجهبندى شده است كه عدد بيشتر نشاندهنده درد

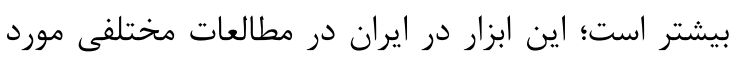

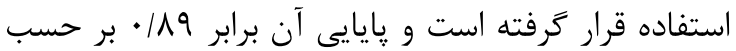
آلفاى كرونباخ است (YY) - (T). ملاحظات اخلاقى در اين مطالعه كه به دقت توسط محققين رعايت شدند همجون ساير مطالعات حيطههاى علوم يزشكى بودند (rQ) و شامل اخذ رضايت آكاهانه،

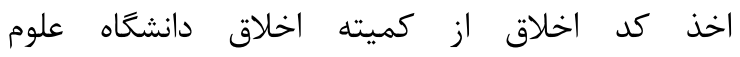
يزشكى تبريز (IR.TBZMED.REC.1397.1059)،

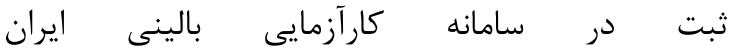
ش كتبن شركت كنندكان، اختيارى بودن شركت در مطالعه، بىخطر

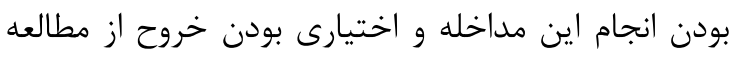

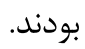
يس از بهدست آوردن اطلاعات لازم در مورد متغيرهاى

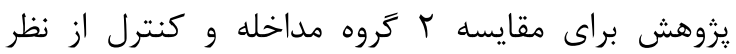

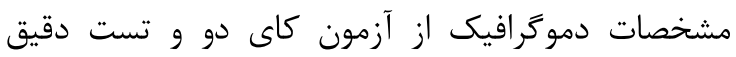

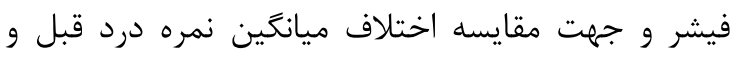
• r ا دقيقه بعد مداخله (كروه مداخله و كنترل) از آزمون تى مستقل جهت مقايسه نتايج دو كروه و همجزنين

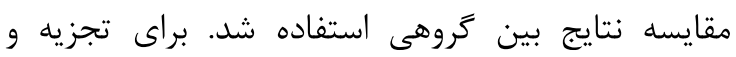

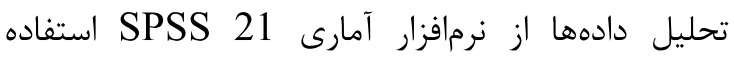
كرديد. P<

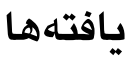

بررسى كل بيماران (VT) نفر) مراجعهكنده به بخش جراحى توراكس بيمارستان امام رضا حاكى از آن بود كه

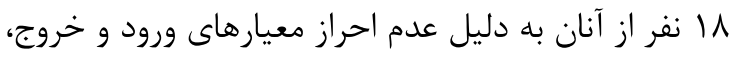

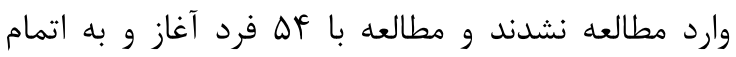
رسيد. بررسى متغيرها با آزمون كولموكروف- اسميرنوف

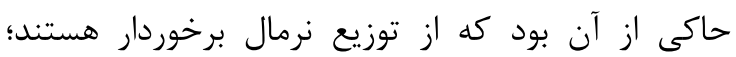

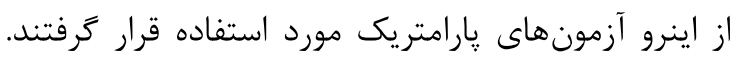

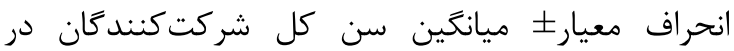

مداخله و تكميل اطلاعات هر فرد در بخش توراكس بيمارستان امامرضا (ع) بود و بيمارانى كه بر اساس فراخ فرات فران طرح تحقيقاتى مربوطه ثبت نام نموده بودند وارد مطالعه

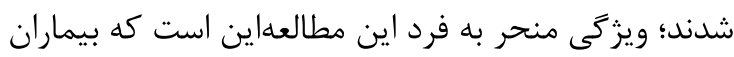
قبل از ماستكتومى، راديوترايى شدهاند.

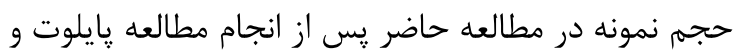

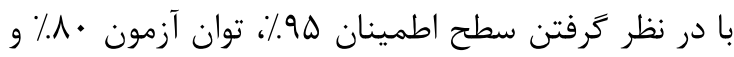

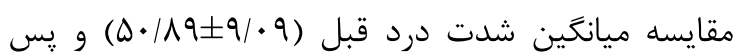

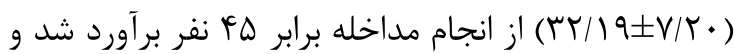
با در نظر گرفتن احتمال ريزش •r درصدى، حجم نمونه

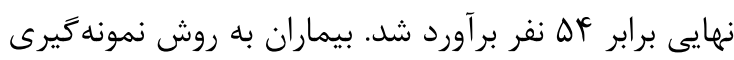

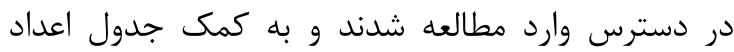

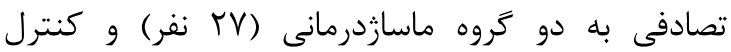

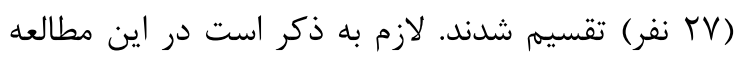

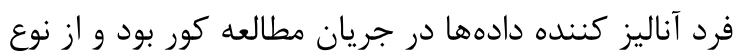
كروهبندى شركت كنندكان بى اطلاع بود (كارآزمايى بالينى

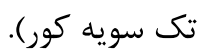
بيماران نيازمند ماستكتومى در ابتدا توسط فوق تخصص توراكس معاينه شده و با توجه به نتايج ماموكرافى، بئى و نظر مشورتى متخصص انكولوزيست كانديد عمل جراحى

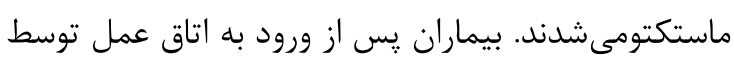
يك متخصص بيهوشى و با روشى يكسان تحت بيهوشى قرار گرفتند و دوز تمامى بيماران يكسان در نظر ترفتئه

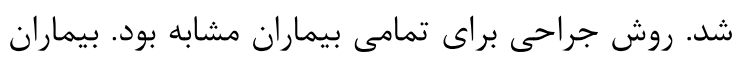

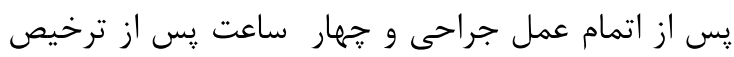
از واحد ريكاورى مداخله مربوطه را دريافت نمودند. ماساز

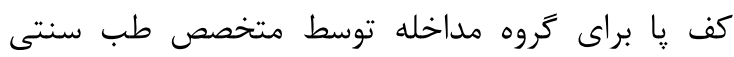
انجام شد به اين شيوه كه هر پا به مدت ده دقيقه به به شيوه קرخشى (دورسى فلكشن و קֶلانتارفلكشن، קرخش به به بيرون و داخل و حركاتى در ياشنه پاها و ساق پاها) ماساز داده شد. جهت از بين بردن اصطكاك بين دست فرد درد

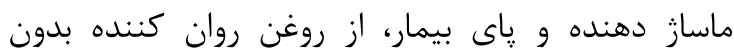

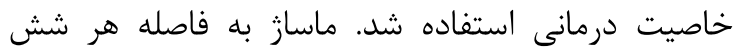

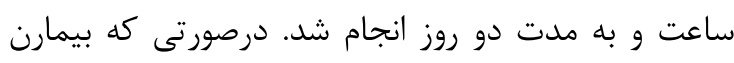

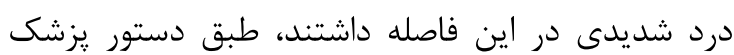

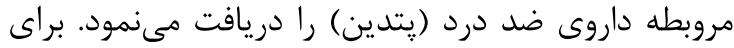

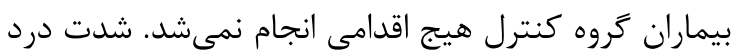

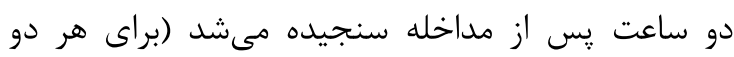
. 


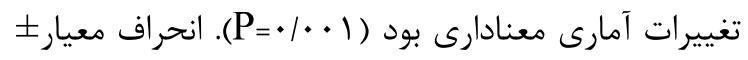
ميانگين ميزان يتدين مصرفى بين دو تروه مدات مداخله

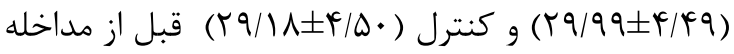

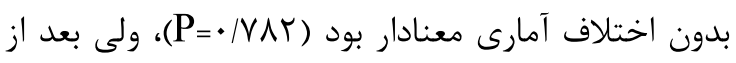

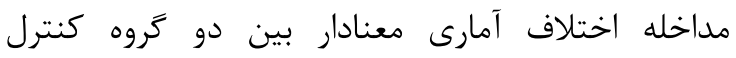

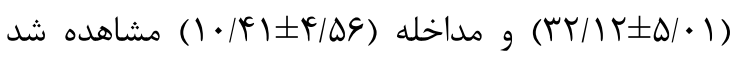

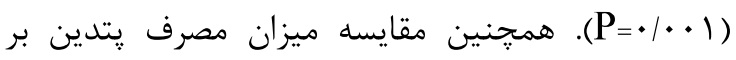

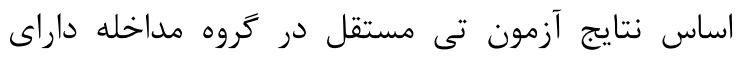

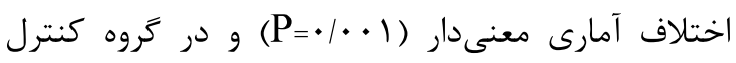

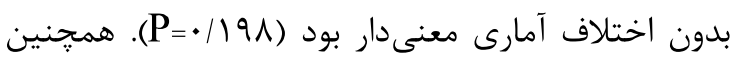

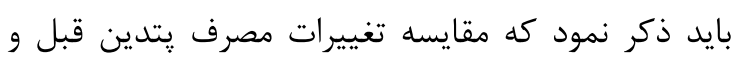

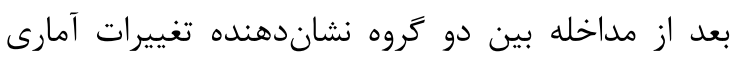

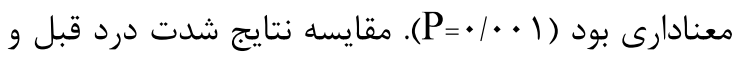

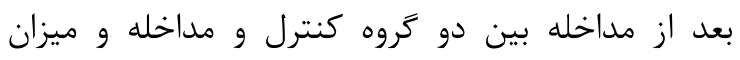
مصرف يتدين در جدول ب آمده است.

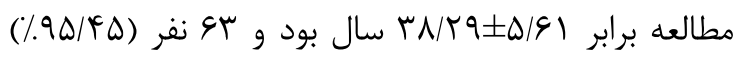

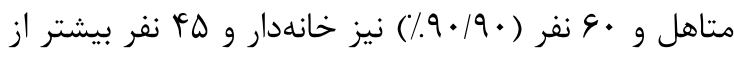

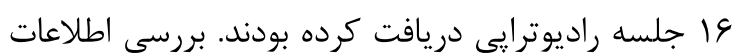

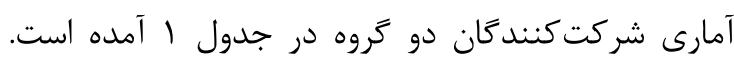

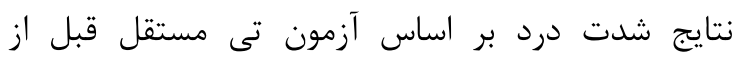

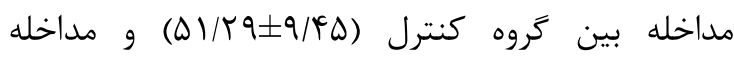

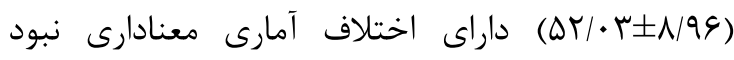

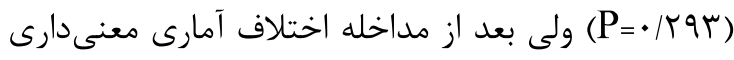

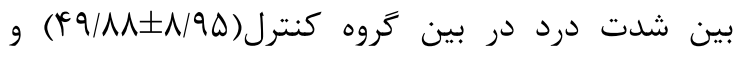

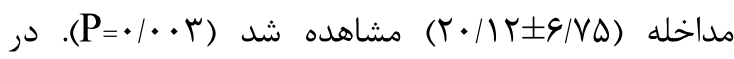
خصوص مقايسه تفاوت قبل و بعد از مداخله بر اساس

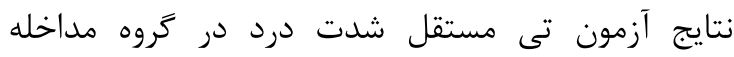

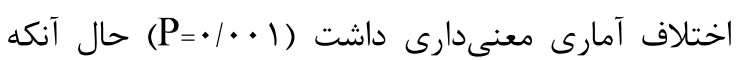

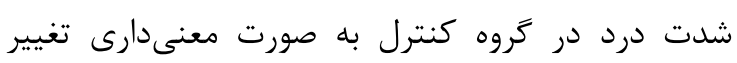

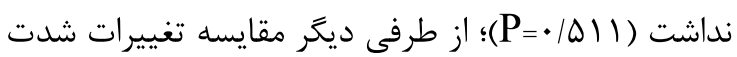

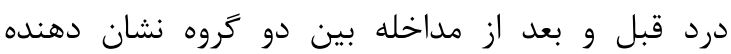

جدول ا: مقايسه مشخصات دموكرافيك شركت كنندگان در مطالعه

\begin{tabular}{|c|c|c|c|}
\hline \multirow[t]{2}{*}{ P Value } & \multicolumn{2}{|c|}{ تروههاى مداخله (n=AF) } & \multirow[t]{2}{*}{ متغير مورد بررسى } \\
\hline & تروه مداخله (n=rV) & كروه كنترل (n=rv) & \\
\hline$* \cdot / 719$ & $\varepsilon q / / q \pm \Lambda / r \mid$ & $4 q / / 9 \pm \Lambda / r \mid$ & سن بر حسب سال (Mean (MSD) \\
\hline$* * / \Gamma \mid \Lambda$ & $\begin{array}{l}G(Y Y \% / Y Y) \\
r I(V V \% / V \Lambda)\end{array}$ & $\begin{array}{l}\Lambda(r q \% / / \& r) \\
19(V \cdot \% / r \Lambda)\end{array}$ & مجريت \\
\hline$* * / r q r$ & $\begin{array}{l}\mid r(F \wedge \% /|| F) \\
\mid F(\Delta|\%| \wedge \varepsilon)\end{array}$ & $\begin{array}{l}11(F \cdot \% / V \Psi) \\
19(\Delta 9 \% / r q)\end{array}$ & تحصيلات \\
\hline$* *|f| \mid$ & $\begin{array}{l}\text { YI(VV\%/IVA) } \\
9(\text { (YY/IYr) }\end{array}$ & $\begin{array}{l}r \cdot(V \psi \% / / \cdot \Lambda) \\
V(r \Delta \% / . / q r)\end{array}$ & شيكار \\
\hline$* * / r \Delta q$ & $\begin{array}{l}I V(\& Y \% / 9 q) \\
1 \cdot(r V \% / / \cdot F)\end{array}$ & $\begin{array}{l}\mid \Delta(\Delta \Delta \% / \mid \Delta \Delta) \\
\mid r(\mid F \psi / / F \Delta)\end{array}$ & تعداد جلسترات راديوترايى از \\
\hline
\end{tabular}

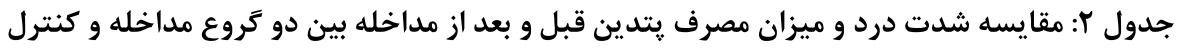

\begin{tabular}{|c|c|c|c|c|}
\hline P Value & كروه مداخله (n=rV) & كروه كنترل (n=rV) & & متغير مورد بررسى \\
\hline . / Rar & $\Delta r / \cdot r \pm \Lambda / q Q$ & $\Delta) / r q \pm q / f \Delta$ & قبل از مداخله & \multirow{3}{*}{ 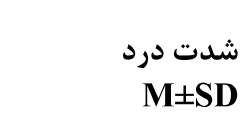 } \\
\hline \multirow[t]{2}{*}{$\cdot . \cdot r$} & $r \cdot / r \pm \& / V \Delta$ & $\vdash q / \Lambda \Lambda \pm \wedge / q \Delta$ & بعد از مداخله & \\
\hline & $\cdot . . .1$ & $\cdot / 011$ & P Value & \\
\hline •/VAT & $r q / q q \pm r / 4 q$ & $r q / / \Lambda \pm r / \Delta$. & قبل از مداخله & \multirow{3}{*}{$\begin{array}{r}\text { ميزان مصرف يتدين } \\
\text { M } \pm \text { SD }\end{array}$} \\
\hline \multirow[t]{2}{*}{$\cdot 1 \cdot .1$} & $1 \cdot / f \mid \pm F / \Delta \varphi$ & $r T / / T \pm \Delta / \cdot 1$ & بعد از مداخله & \\
\hline &.$/ . .1$ &.$/ 191$ & P Value & \\
\hline
\end{tabular}


افراد مورد مداخله در اين مطالعه و مطالعه ذكر شده داراى

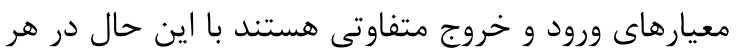
دو مطالعه اثربخشى اين روش تاييد شده است و ويشنهاد مىشود مورد استفاده قرار كيرد.

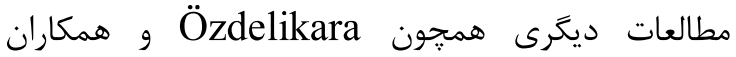

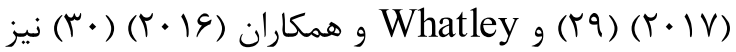

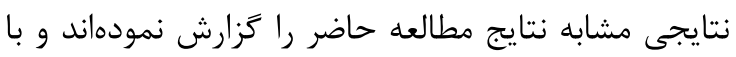
مطالعه حاضر همسو هستند. متعاقب كاهش شدت درد درد نيز مصرف اوييوئيد با كاهش همراه خواهد بود و از اين رو هائر عوارض داروهاى اوييوئيد نيز در اين بيماران به دليل

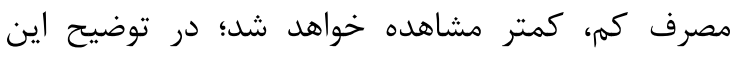

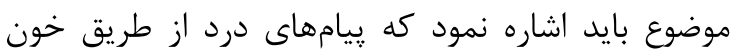

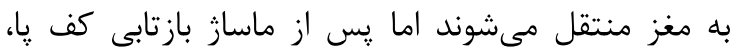

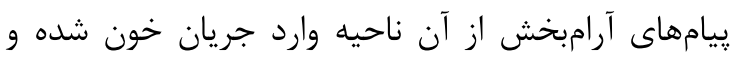

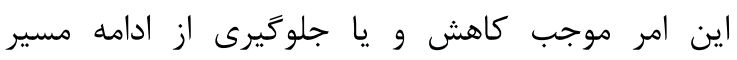

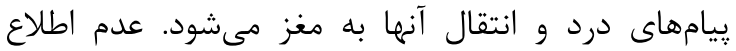
دقيق از دوزهاى مخدر دريافتى در اتاق عمل، عدم كنترل

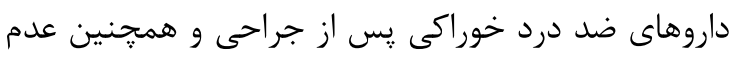

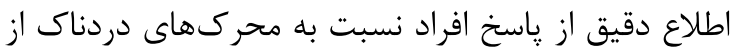
محدوديتهاى استفاده از اين روش هستند با اين حال

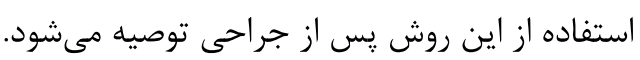

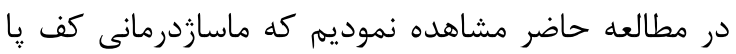

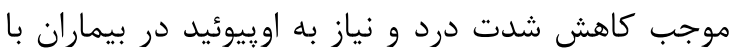
سابقه راديوترابى تحت ماستكتومىشده است. در درد اين

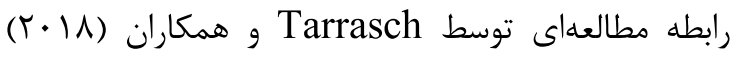

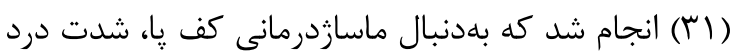

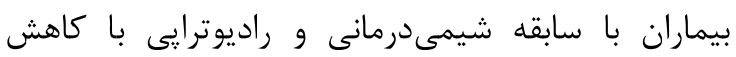

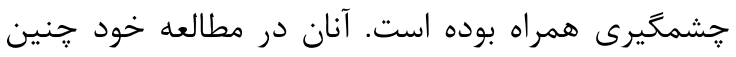

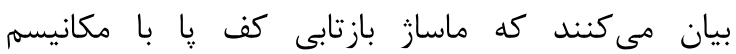
آرامبخشى و ضد دردى كه بر سلول هاى مغزى دارد موجب مانب

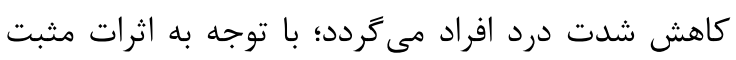
اين مداخله در كاهش شدت درد، انجام آن در برد بيماران آندان

حين شيمىدرمانى و راديوترايى توصيه مىشود.

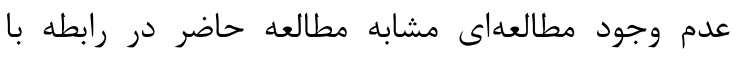
اثرات ماساز بازتابى كف پا در زنان رجان راديوترايى شده كانديد ماستكتومى و اثرات آن بر شدت درد و نياز به اويِيوئيد

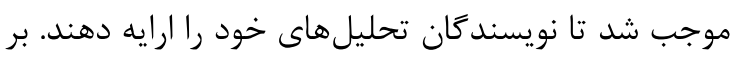

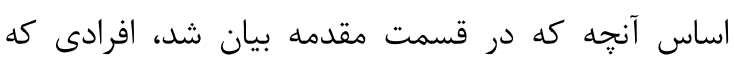
سابقه راديوترابى قبل از جراحى را دارند نسبت به افرادى

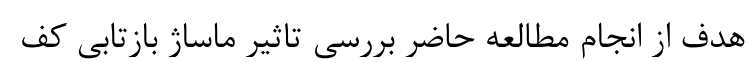

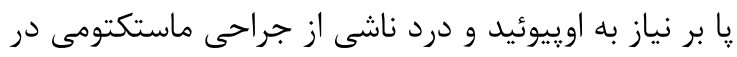

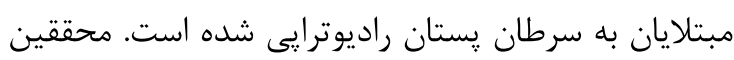

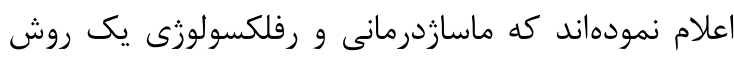

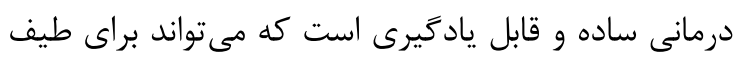

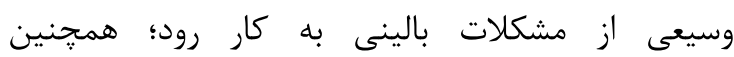

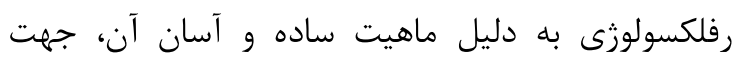

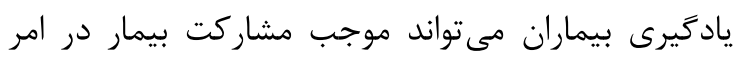

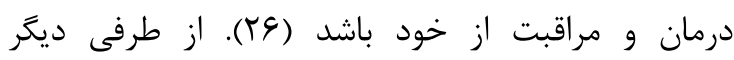
مطالعات نشان دادهاند كه رفلكسولوزى مى تواند با كاهش

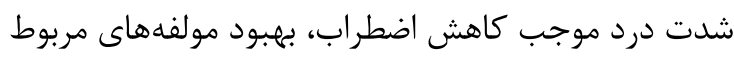

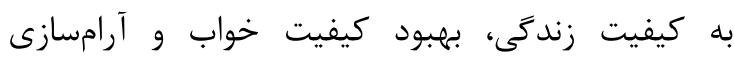

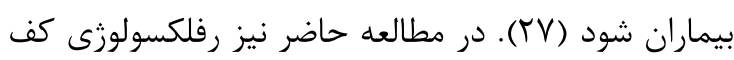

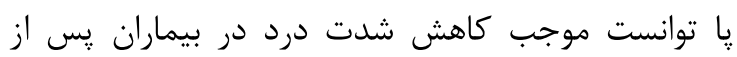

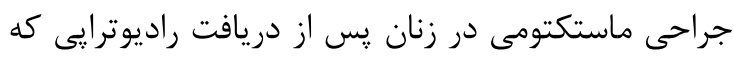

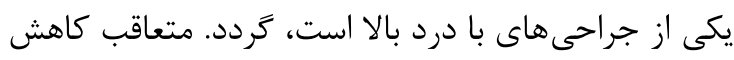

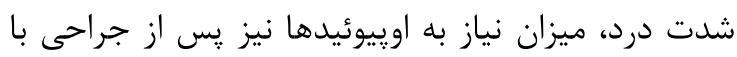

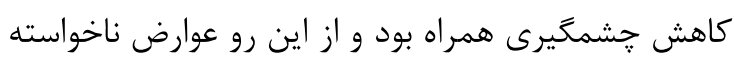

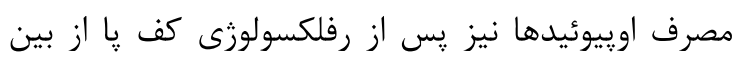

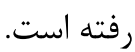
مطالعات زيادى با هدف بررسى اثرات رفلكسولوزى كف پا

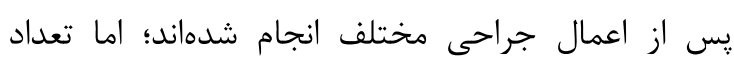

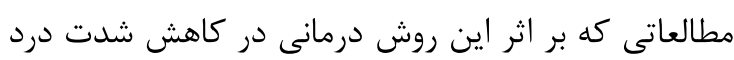

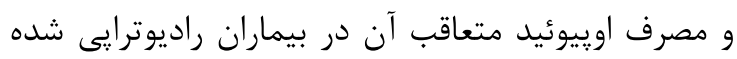

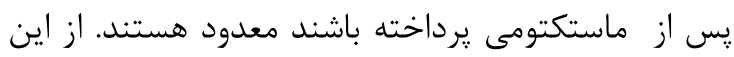

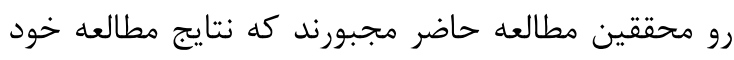

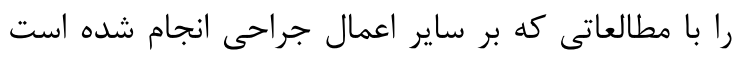

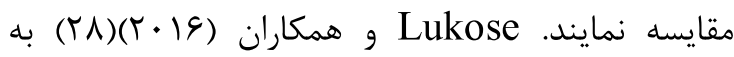

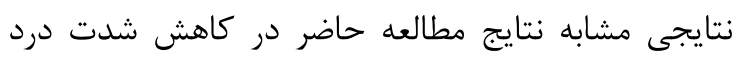

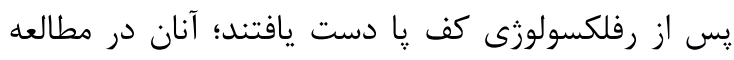

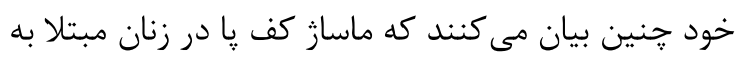

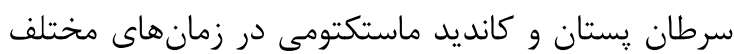

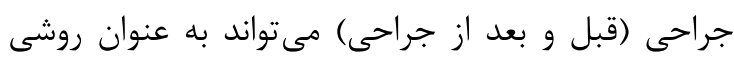

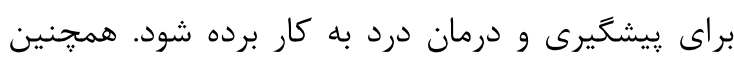

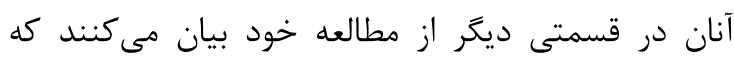

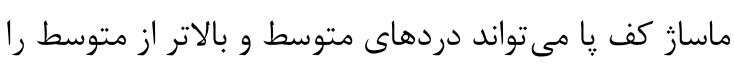

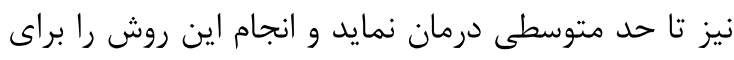

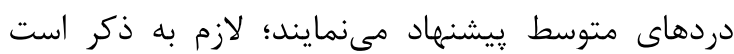


كف پا توانست موجب كاهش شدت درد و نياز به اوِيوئيد

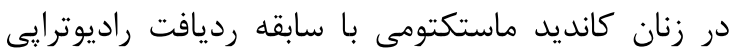

\section{تشكر و قدردانى}

مقاله حاضر بر گرفته از يزوهش مصوب در شوراى تخصصى يزوهش مركز تحقيقات واحد توسعه تحقيقات بالينى بيمارستان شهدا است؛ تمامى نويسندگان از واحد توسعه

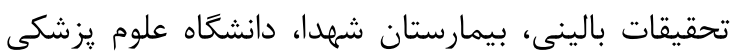
تبريز بخاطر حمايتهاى اين مركز نهايت تشكر را دارند.

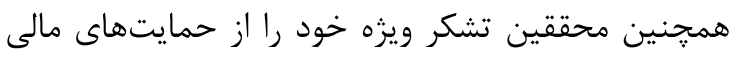
معاونت بهداشتى دانشخاه از اين طرح دارند.

$$
\text { تويسند نعارض اعلام منافع دارند كه هيج تعارض منافعى در }
$$

\section{References}

1. Sangesland A, Støren C, Vaegter HB. Are preoperative experimental pain assessments correlated with clinical pain outcomes after surgery? A systematic review. Scandinavian journal of pain. 2017; 15(1):44-52.

2. Khanbabaei Gol M, Aghamohammadi D. Effect of intravenous infusion of magnesium sulfate on opioid use and hemodynamic status after hysterectomy: double-blind clinical trial. The Iranian Journal of Obstetrics, Gynecology and Infertility. 2019; 22(7):32-8. doi: 10.22038/ijogi.2019.13815.

3. Aghamohammadi D, Gargari RM, Fakhari S, Bilehjani E, Poorsadegh S. Classic versus Inguinal Approach for Obturator Nerve Block in Transurethral Resection of Bladder Cancer under Spinal Anesthesia: A Randomized Controlled Trial. Iranian journal of medical sciences. 2018; 43(1):75-80.

4. Nir RR, Nahman-Averbuch H, Moont R, Sprecher E, Yarnitsky D. Preoperative preemptive drug administration for acute postoperative pain: A systematic review and meta-analysis. European Journal of Pain. 2016; 20(7):1025-43. doi: https://doi.org/10.1002/ejp.842.

$$
\begin{aligned}
& \text { كه اين سابقه را ندارند از درد بيشترى زجر مىبرند و درد } \\
& \text { اين افراد يس از جراحى در دسته دردهاى بالاتر از متوسط }
\end{aligned}
$$

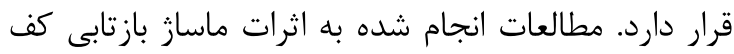

$$
\begin{aligned}
& \text { يا در كاهش شدت دردهاى متوسط اشاره نمودهاند اما }
\end{aligned}
$$

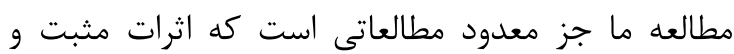

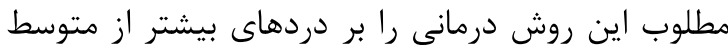

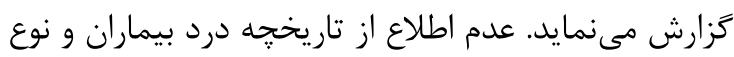

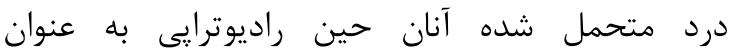

$$
\begin{aligned}
& \text { محدوديت مطالعه حاضر است. محققين انجام مطالعات } \\
& \text { بيشتر براى دردهاى بالاتر از متوسط را ييشنهاد مى كنند. }
\end{aligned}
$$

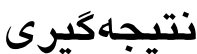

$$
\begin{aligned}
& \text { درد بعد از عمل جراحى ماستكتومى شايع است و سابقه } \\
& \text { راديوترايى قبل از آن نيز مى تواند موجب افزايش إنى شدات } \\
& \text { درد در بيماران شود؛ انجام اقدامات غير دارويى در كنار }
\end{aligned}
$$

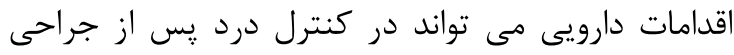

$$
\begin{aligned}
& \text { موثر باشد؛ در اين مطالعه مشاهده شد كه ماساز بازتابى }
\end{aligned}
$$

5. Montazer M, Hadadi Z, Ghavami Z, Khanbabaei Gol M. Relationship of Body Mass Index with Chronic Pain after Breast Surgery in Women with Breast Cancer. The Iranian Journal of Obstetrics, Gynecology and Infertility. 2019; 22(8):10-8. doi: 10.22038/ijogi.2019.13915.

6. Fakhim SA, Shahidi N, Lotfi A. Prevalence of associated anomalies in cleft lip and/or palate patients. Iranian journal of otorhinolaryngology. 2016; 28(85):135-139.

7. Yang MM, Hartley RL, Leung AA, Ronksley PE, Jetté N, Casha S, et al. Preoperative predictors of poor acute postoperative pain control: a systematic review and meta-analysis. BMJ open. 2019; 9(4):e025091. doi: http://dx.doi.org/10.1136/bmjopen-2018-025091.

8. Wang L, Guyatt GH, Kennedy SA, Romerosa B, Kwon HY, Kaushal A, et al. Predictors of persistent pain after breast cancer surgery: a systematic review and meta-analysis of observational studies. Cmaj. 2016; 188(14):E352E61.

9. Gol MK, Dadashzadeh M, Anvari HM. Design and Implementation of a Checklist for Prediction of Anesthesia-Induced Nausea and Vomiting in Candidate Patients for Mastectomy. International 
Journal of Women's Health and Reproduction Sciences. 2020; 1(1):90-4. doi: 10.15296/ijwhr.2020.13.

10. Lovett-Carter D, Kendall MC, McCormick ZL, Suh EI, Cohen AD, De Oliveira GS. Pectoral nerve blocks and postoperative pain outcomes after mastectomy: a meta-analysis of randomized controlled trials. Regional Anesthesia \& Pain Medicine. 2019; 1(1): 100658-100668.

11. Aghamohammadi D, Mehdinavaz Aghdam A, Khanbabayi Gol M. Prevalence of Infections Associated with Port and Predisposing Factors in Women with Common Cancers Under Chemotherapy Referred to Hospitals in Tabriz in 2015. The Iranian Journal of Obstetrics, Gynecology and Infertility. 2019; 21(11):7-13. doi: 10.22038/ijogi.2019.12321.

12. Khanbabaei Gol M, Rezvani F, Ghavami Z, Mobaraki-Asl N. Prevalence of neuropathic pain and factors affecting sleep quality in women with breast cancer after radiotherapy. The Iranian Journal of Obstetrics, Gynecology and Infertility. 2019; 22(6):46-53. doi: 10.22038/ijogi.2019.13743.

13. Humble S, Dalton A, Li L. A systematic review of therapeutic interventions to reduce acute and chronic post-surgical pain after amputation, thoracotomy or mastectomy. European Journal of Pain. 2015; 19(4):451-65.

14. Wynne R, Lui N, Tytler K, Koffsovitz C, Kirwa $\mathrm{V}$, Riedel B, et al. The Trajectory of Postoperative Pain Following Mastectomy with and without Paravertebral Block. Pain Management Nursing. 2017; 18(4):234-42.

15. Larsson IM, Ahm Sørensen J, Bille C. The Postmastectomy Pain Syndrome-A Systematic Review of the Treatment Modalities. The breast journal. 2017; 23(3):338-43.

16. Aghamohamadi D, Gol MK. Checklist for Determining Severity of Pain and Type and Dosage of Analgesics Administered to Patients Undergoing Breast Surgeries. International Journal of Women's Health and Reproduction Sciences. 2020; 8(2):227-31. doi: 10.15296/ijwhr.2020.36.

17. Tait RC, Zoberi K, Ferguson M, Levenhagen K, Luebbert RA, Rowland K, et al. Persistent postmastectomy pain: risk factors and current approaches to treatment. The Journal of Pain. 2018;19(12):1367-83.

18. Field T. Massage therapy research review. Complementary therapies in clinical practice. 2016; 24(1):19-31.

19. McVicar A, Greenwood C, Ellis C, LeForis C. Influence of study design on outcomes following reflexology massage: an integrative and critical review of interventional studies. The Journal of
Alternative and Complementary Medicine. 2016; 22(9):739-50.

20. Nourmohammadi H, Motaghi M, Borji M, Tarjoman A, Soltany B. The Effects of Reflexology on Fatigue Severity of Patients with Cancer. Asian Pacific journal of cancer prevention: APJCP. 2019; 20(2):391-4.

21. Khazaei T, Rezaei Mohabbati S, Sebzari A, Hosseini M. The effect of foot reflexology massage on the stress and neuropathic pain caused by chemotherapy in women with breast cancer and genitalia. J Birjand Univ Med Sci. 2019; 26(1):4-12.

22. Naseri-Salahshour V, Sajadi M, Abedi A, Fournier A, Saeidi N. Reflexology as an adjunctive nursing intervention for management of nausea in hemodialysis patients: A randomized clinical trial. Complementary Therapies in Clinical Practice. 2019; 36(1):29-33.

23. Ilhan E, Chee E, Hush J, Moloney N. The prevalence of neuropathic pain is high after treatment for breast cancer: a systematic review. Pain. 2017; 158(11):2082-91.

24. Ranjkesh F, Mehri Z, Mafi M, Habibi M, Moafi F. Effects of acupressure at LI4, He7, SP6 and Neima points on labor anxiety in nulliparous women: randomized clinical trial. The Iranian Journal of Obstetrics, Gynecology and Infertility. 2019; 22(4):25-35. doi: 10.22038/ijogi.2019.13442.

25. Darghahi R, Mobaraki-Asl N, Ghavami Z, Pourfarzi F, Hosseini-Asl S, Jalilvand F. Effect of cell-free fetal DNA on spontaneous preterm labor. Journal of advanced pharmaceutical technology \& research. 2019; 10(3):117-124. doi: 10.4103/japtr.JAPTR_371_18.

26. Watson S. The effects of massage: an holistic approach to care. Nursing standard (Royal College of Nursing (Great Britain): 1987). 1997;11(47):45-7. doi: 10.7748/ns.11.47.45.s47.

27. Stephenson NL, Swanson M, Dalton J, Keefe FJ, Engelke M, editors. Partner-delivered reflexology: effects on cancer pain and anxiety. Oncology nursing forum; 2007; 34(1):132-36.

28. Lukose N, Pavithran S, Anu K. Effect of Foot Reflexology as an Add-on Intervention on Pain Among Women Having Undergone Mastectomy. The Nursing journal of India. 2016; 107(4):15962.

29. Özdelikara A, Tan M. The effect of reflexology on the quality of life with breast cancer patients. Complementary therapies in clinical practice. 2017; 29(2):122-9.

30. Whatley J, Street R, Kay S, Harris PE. Use of reflexology in managing secondary lymphoedema for patients affected by treatments for breast cancer: A feasibility study. Complementary therapies in clinical practice. $2016 ; 23: 1-8$. 
31. Tarrasch R, Carmel-Neiderman NN, Ben-Ami S, Kaufman B, Pfeffer R, Ben-David M, et al. The effect of reflexology on the pain-insomnia-fatigue disturbance cluster of breast cancer patients during adjuvant radiation therapy. The Journal of Alternative and Complementary Medicine. 2018; 24(1):62-8. 